\title{
STABILITY OF PHANTOM LIMB PHENOMENA AFTER UPPER LIMB AMPUTATION: A LONGITUDINAL STUDY
}

\author{
J. P. HUNTER, ${ }^{b, c}$ J. KATZ ${ }^{c, d, e, f}$ AND K. D. DAVIS ${ }^{a, c, g *}$ \\ aDivision of Brain, Imaging and Behaviour-Systems Neuroscience, \\ Toronto Western Research Institute, University Health Network, To- \\ ronto Western Hospital, 399 Bathurst Street, Room MP14-306, To- \\ ronto, Ontario, Canada M5T 258 \\ ${ }^{b}$ Department of Physical Therapy, University of Toronto, Toronto, On- \\ tario, Canada \\ 'Institute of Medical Science, University of Toronto, Toronto, Ontario, \\ Canada \\ 'Department of Psychology and School of Kinesiology and Health \\ Science, York University, Toronto, Ontario, Canada \\ eDepartment of Anesthesia and Pain Management, University Health \\ Network and Mount Sinai Hospital, Toronto, Ontario, Canada \\ 'Department of Anesthesia, University of Toronto, Toronto, Ontario, \\ Canada \\ ${ }^{g}$ Department of Surgery, University of Toronto, Toronto, Ontario, Can- \\ ada
}

Abstract-Amputees may experience stump pain (SP), phantom limb (PL) sensations, pain, and/or a general awareness of the missing limb. The mechanisms underlying these perceptions could involve nervous system neuroplasticity and be reflected in altered sensory function of the residual limb. Since little is known about the progression of post-amputation sensory phenomena over time, we longitudinally evaluated the stability of, and relationships among: 1) subjective reports of PL sensations, pain, awareness, and SP, 2) stump tactile and tactile spatial acuity thresholds, and 3 ) use of a functional vs. a cosmetic prosthesis in 11 otherwise healthy individuals with recent unilateral, traumatic upper-extremity amputation. Subjects were evaluated within 6 months and at 1-3 years after amputation. Processing of tactile sensory information from the stump remained stable over the study time period. PL awareness was frequent, stable over time, intense, and occurred with or without PL sensations. Functional prosthetic use correlated with stable vividness of PL awareness whereas subjects who used a cosmetic prosthesis had less vivid PL awareness at follow-up. Initial SP correlated with follow-up SP, the initial PL pain correlated with follow-up PL pain but neither initial nor follow-up SP appear to be related to follow-up PL pain after accounting for initial PL pain intensity. Neither limb temperature nor prosthesisuse correlated with the initial vs. follow-up change in PL pain intensity. These data provide evidence that $P L$ pain described 1-3 years after an amputation is not related in any simple way to peripheral sensory function, SP, or limb temperature; and

${ }^{*}$ Correspondence to: K. D. Davis, Division of Brain, Imaging and Behavior-Systems Neuroscience, Toronto Western Research Institute, University Health Network, Toronto Western Hospital, 399 Bathurst Street, Room MP14-306, Toronto, Ontario, Canada M5T 2S8. Tel: +1-416-603-5662; fax: +1-416-603-5745

E-mail address: kdavis@uhnres.utoronto.ca (K. D. Davis).

Abbreviations: ANOVA, analysis of variance; $\mathrm{CP}$, cosmetic prosthesis;

FP, functional prosthesis; $\mathrm{PL}$, phantom limb; $\mathrm{SP}$, stump pain; $\mathrm{S1}$ primary somatosensory cortex.
PL awareness but not PL pain may be influenced by the frequent use of a functional prosthesis. (c) 2008 IBRO. Published by Elsevier Ltd. All rights reserved.

Key words: amputation, plasticity, perception, quantitative sensory testing, psychophysics.

Almost every individual with an amputation experiences sensory phenomena that are perceived to originate from the missing body part (Jensen et al., 1985; Sherman, 1997; Kooijman et al., 2000; Nikolajsen and Jensen, 2005). These "phantom limb" (PL) perceptions include a general awareness of the existence of the missing body part (PL awareness) (Halligan, 2002; Hunter et al., 2003), or more specific nonpainful somatic sensations such as tingling, itching, pressure, warmth, or cold (PL sensations) (Jensen et al., 1984). Many individuals also experience post-amputation pain that appears to originate in the missing limb (PL pain) and/or residual limb (stump) pain (SP) Acute post-surgical amputation pain is not surprising considering the devastating nature of the injury, which includes the severing of large peripheral nerves. However, in many individuals, post-amputation pain persists even after healing has occurred and the mechanisms underlying this persistent neuropathic pain remain enigmatic. There is evidence that both peripheral (Devor and Seltzer, 1999) and central (Mannion and Woolf, 2000) nervous system processes contribute to phantom sensory phenomena and pain, but the relative contribution of each is unclear (Melzack, 1990; Katz, 1992b). A better understanding of the underlying neural mechanism(s) is needed to develop effective treatment strategies for PL pain (Woolf and Mannion, 1999) or, as recently described, to use the innocuous $\mathrm{PL}$ awareness as part of rehabilitation treatments to improve function or decrease pain disability (Moseley, 2006).

Much of what is known about PL phenomena is based on cross-sectional data obtained from subjects who were evaluated several years after their amputations. Thus, it is not clear the extent to which longstanding PL sensations, pain, awareness, and SP reflect early post-amputation sensation and/or pain because most studies evaluate this time period retrospectively. The few longitudinal studies that exist have shown that the quality and intensity of $P L$ sensations and $\mathrm{PL}$ pain can change over time. The prevalence of $P L$ sensations and the frequency of episodes of PL sensations may be highest within 6 months post-operatively after upper extremity (Carlen et al., 1978) or lower extremity (Jensen et al., 1984) amputation. In a group of lower-extremity amputees measured over the first 2 years after elective amputation surgery, Jensen et al. (1984 
1985) reported that the incidence of PL sensations and PL pain decreased, the perceived location shifted to a more distal portion of the missing limb, and the character of both $\mathrm{PL}$ sensations and PL pain changed. However, since the majority of subjects in these studies had diabetes or peripheral vascular disease, it is unclear if longstanding preamputation pain or coexisting systemic disease influenced these results. In contrast, traumatic upper extremity amputation commonly occurs in a younger population and without longstanding pre-amputation pain or other systemic illnesses. There are no systematic longitudinal evaluations of the stability of post-amputation sensory phenomena within the first 2 years after upper extremity traumatic amputation.

The relationship between early and late $\mathrm{PL}$ pain and $\mathrm{SP}$ may provide insight into the mechanisms underlying these perceptions. At the level of the spinal cord, noxious input in the early post-amputation time period can induce central sensitization (Mannion and Woolf, 2000) which may underlie and exacerbate coexisting or chronic $\mathrm{PL}$ pain. However, there is conflicting evidence regarding the relationship between SP and PL pain. For example, Carlen et al. (1978) and Steinbach et al. (1982) observed that patients noted a decrease in $P L$ pain when stump end pathology (i.e. scar infection and bony necrosis) resolved. Some cross-sectional studies have reported that more subjects with SP (vs. without SP) also experience PL pain (Sherman et al., 1984; Kooijman et al., 2000; Dijkstra et al., 2002), but others found no such association between chronic SP and PL pain (Jensen et al., 1985; Nikolajsen et al., 1997; Fraser et al., 2001; Gallagher et al., 2001; Hanley et al., 2007). The longitudinal studies of lower extremity amputees do not support a relationship between persistent PL pain and co-existing SP (Jensen et al., 1985; Nikolajsen et al., 1997), but interpretation of these studies is difficult because subjects had coexisting disease that could have affected peripheral nerve function.

At the cortical level, evidence for reorganization of the primary somatosensory cortex (S1) after upper extremity amputation appears to vary with PL pain intensity, prosthesis-use, and tactile training (Flor et al., 1995, 2006). Interestingly, amputees that frequently and extensively used a myoelectric prosthesis showed less cortical reorganization and lower intensity of PL pain than those who did not use the prosthesis extensively (Lotze et al., 1999). Since animal studies have provided evidence that behaviorally relevant tactile stimulation expands the cortical representation of the stimulated body region (Jenkins et al., 1990; Recanzone et al., 1992), the above findings suggest that purposeful limb use may decrease maladaptive plasticity (Flor et al., 2006) and PL pain (Katz, 1992a). Daily operation of a functional (mechanical or myoelectric) prosthesis is purposeful use of the amputated limb. However, to the best of our knowledge there are no longitudinal data regarding the effect of functional prosthesis (FP) use on the stability of PL phenomena or the stability of tactile processing.

Another factor that has not been examined longitudinally is the role of sympathetic nervous system activity on
$P L$ pain. It is consistently reported that the residual limb (stump) is usually cooler than the unaffected limb (Sliosberg, 1948; Angrilli and Koster, 2000). Sherman and Bruno (1987) reported that the minute-by-minute fluctuations in stump skin temperature and PL pain intensity correlated inversely. They proposed that a lower surface temperature of the stump reflected sympathetic hyperactivity, resulting in reduced blood flow to the stump, and secondary pain. However, there are no longitudinal data describing the relationship between limb temperature and stump or $\mathrm{PL}$ pain intensity, particularly in individuals without co-existing peripheral vascular disease.

The aim of the present study was to longitudinally evaluate the stability of limb temperature, sensory processing of tactile information from the stump, and individual subjective reports of phantom and stump sensory phenomena in a group of individuals with traumatic upper extremity amputation but who are otherwise healthy. We further evaluated the relationships between early $(<6$ months) and later (24 months) (1) SP and PL perceptions, (2) prosthesis-use and PL perceptions, (3) prosthesis-use and stump tactile spatial acuity, and (4) stump temperature and intensity of stump or PL pain.

\section{EXPERIMENTAL PROCEDURES}

\section{Subjects}

Subjects had all undergone traumatic unilateral below-shoulder amputation and were recruited from our two previous studies (Hunter et al., 2003, 2005). From this group, all subjects who lived in reasonable proximity and who were initially evaluated less than 6 months after injury were contacted for a follow-up session at least 11.5 months after the initial session. Of the 14 subjects who were eligible for the follow-up session, three refused participation because of geographical distance, leaving a subset of 11 subjects who were re-examined at the follow-up session.

As previously described (Hunter et al., 2005), our method of sampling ensured that the subject cohort was inclusive of upper extremity amputees at the two rehabilitation institutions from which subjects were recruited, and not limited to those with pain or other sensory symptoms. In addition, subjects were excluded if the mechanism of injury may have included traction to the brachial plexus, or if they had a history of pre-amputation sensory dysfunction, or coexisting medical problems (e.g. diabetes or vascular or neurological disease) that would interfere with sensory testing or peripheral vascular physiology. Informed consent was obtained from all subjects at the time of recruitment, prior to participation in the study.

\section{Study design}

All subjects were interviewed by one author (J.P.H.) in a quiet room, free from temperature fluctuations, drafts, and noise. Each subject underwent the same semi-structured interview that we previously conducted upon their inclusion in our earlier studies (Hunter et al., 2003, 2005). Characteristics of spontaneous stump and phantom sensory phenomena, tactile-evoked PL percepts, evoked SP (subjective reports of hyperalgesia, neuromas, or allodynia), and prosthesis-use were documented and medical history was updated. Stump skin temperature, tactile thresholds, and tactile spatial acuity were then measured. The interview and psychophysical examination data were entered manually on a paper questionnaire (J.P.H.) at the time of the interview and examination. The sessions were also videotaped and later reviewed to 
ensure complete and accurate data collection. A second evaluator (K.D.D.) also reviewed a selection of the tapes for quality control During each psychophysical measurement the subject was asked to keep his or her eyes closed.

\section{Evaluation of stump and phantom sensory phenomena}

Each subject was asked to describe the current perceived size, shape, movement, and thermal qualities of the PL as well as the location, quality, frequency and intensity of painless and painful stump and phantom awareness and sensations. Each of these qualities was assessed by open-ended questions followed by specific questions for clarification. In order to be consistent with our previous study, subjects asked to report the intensity of SP, PL sensations, pain, or awareness experienced within the last week. The intensity of their "usual" spontaneous phantom and SP was rated on a $10 \mathrm{~cm}$ visual analog scale, with the text anchors: "no pain" and "worst pain imaginable" at zero and 10 respectively. Pearson linear correlation and partial correlation analyses were used to evaluate the concurrent and predictive relationship between SP intensity and phantom pain intensity at the initial and follow-up sessions.

\section{Documentation of prosthesis-use}

During the interview, subjects were asked to describe their daily prosthesis-use including type of prosthesis (functional vs. cosmetic) (Fraser, 1998) and amount of time the prosthesis was worn during each day. A prosthesis was defined as an FP if it could be manipulated by the subject for physical-function purposes. This category included myoelectric and mechanical (cable-operated) prostheses. A "cosmetic prosthesis" (CP) was defined as any prosthesis that was designed for cosmetic purposes only and not for physical function. At follow-up session, all subjects had been fitted with a prosthesis for more than 6 months and were thus divided into two groups based on the type of prosthesis they reported using. The effect of prosthesis type on the intensity of stump and PL pain, and vividness of PL awareness at follow-up was tested with an analysis of variance (ANOVA). The effect of type of prosthesis (FP vs. CP) on intersession change in intensity of SP, PL pain, and vividness of PL awareness was tested with an ANOVA. Significance for both analyses was set at $P<0.05$.

\section{Tactile detection and spatial acuity thresholds}

Psychophysical measures included tactile detection thresholds (Touch TestTM Sensory Evaluator, Stoelting, Wood Dale, IL, USA) and two-point discrimination thresholds to test tactile spatial acuity (Model 16011 Two-Point Aesthesiometer; Layfayette Instrument Company, Lafayette, IN, USA). Thresholds were tested at sites on the upper limbs proximally and distally near the tip of the stump and at homologous sites on the intact limb. Criteria for site selection on the amputated side and criteria for determination of thresholds were previously described (Hunter et al., 2005). Two locations on the amputated side were selected for testing: (i) the "stump tip" measurement was within $5 \mathrm{~cm}$ of the tip of the stump; (ii) the "proximal site" measurement was mid-forearm (except for patient $F 7$, for whom it was mid-arm). All thresholds were compared between the stump and the homologous site (paired $t$-test) and between initial and follow-up measures.

All data are presented as mean \pm standard error, with the exception of the subject characteristics which are presented as mean \pm standard deviation.

\section{Skin temperature}

Skin temperature was measured with a $1 \mathrm{~cm}$ diameter surface probe (Model P-08440-00; Cole-Parmer, Chicago, IL, USA) con- nected to a digital thermistor thermometer (Model 8110-20; ColeParmer). To examine the change in stump skin temperature between the initial session and the follow-up session, skin temperature was measured at two sites, the "stump tip" and the "proximal site." Selection of follow-up sites was based on written description of the initial sites.

Skin temperatures from the amputated side were compared with homologous sites on the intact side (paired $t$-test). The variables, visit (initial/follow-up), side (stump/intact), and site (proximal/distal) were modeled with a three-way repeated measures ANOVA. Post hoc analysis of individual pairwise comparisons for simple main effects used the Sidak adjustment for multiple comparisons, with corrected $P<0.05$.

The relationship between stump skin temperature and the intensity of the individual's phantom pain or SP was evaluated by Pearson linear correlation analysis. Significance was set at $P<0.004$ (alpha $=0.05$, adjusted using a Bonferroni type 1 error rate correction for multiple comparisons).

\section{RESULTS}

\section{Characteristics of subjects}

The subjects were initially evaluated at an average of $4.6 \pm 1.6$ months after amputation (Table 1). At follow-up, the mean time since amputation was $28.3 \pm 9.4$ months. The mean intersession interval was $24 \pm 9.1$ months. The mean ( \pm S.D.) age of the 11 subjects at follow-up was 35.4 $( \pm 11.8)$ years. Prosthesis-use at follow-up is shown in Table 1. At the initial visit, only three subjects had been fitted with a prosthesis; subject F7 reported using a mechanical prosthesis more than $5 \mathrm{~h}$ per day; subject $\mathrm{F} 10$ used a mechanical prosthesis less than $3 \mathrm{~h} /$ day; and subject $F 11$ used a mechanical prosthesis more than $8 \mathrm{~h} /$ day. At follow-up, all subjects except subject F9 had been fitted with either a cosmetic or a FP for at least 1 year. Subject F9 had been using a CP for 6 months.

\section{Nonpainful phantom phenomena}

All but one subject (F4) experienced an awareness of the $\mathrm{PL}$ at the initial session (Table 2). At follow-up, this subject (F4) and one additional subject (F5) did not experience PL awareness. Thus, the prevalence of PL awareness was not significantly different at follow-up from the initial session $\left(\chi^{2}=0.386, P=0.53\right)$. The vividness of $P L$ awareness (refer to Fig. 1) was consistently high in most subjects at both the initial session and the follow-up session. That is, all subjects who experienced $\mathrm{PL}$ awareness at both sessions rated vividness as at least $7 \mathrm{~cm}$ on a $10 \mathrm{~cm}$ VAS scale and verbally described the vividness intensity as similar at both sessions. The mean vividness rating at follow-up was similar to the initial session; the mean \pm S.E. change in vividness was only $0.95 \pm 0.39 / 10$.

Of the nine subjects who continued to experience non-painful phenomena, two subjects (F1 and F9) reported that the PL sensations had changed from steady to intermittent. At the initial session eight subjects reported that their phantom hand was positioned in a fixed neutral or flexed position; this perception was similar in all eight subjects at the follow-up session. With respect to the PL sensation qualities of "tickling," "tingling," and 
Table 1. Characteristics of follow-up subjects

\begin{tabular}{|c|c|c|c|c|c|c|c|}
\hline \multirow[t]{2}{*}{ Subject } & \multirow[t]{2}{*}{ Age/sex } & \multirow[t]{2}{*}{ Level and side (L/R) ${ }^{a}$} & \multicolumn{2}{|c|}{$\begin{array}{l}\text { Months post- } \\
\text { amputation }\end{array}$} & \multicolumn{3}{|c|}{ Current prosthesis-use (h/day) } \\
\hline & & & Initial & Follow-up & Cosmetic & Mechanical & Myoelectric \\
\hline F1 & $31 / \mathrm{M}$ & Midcarpal (L) & 2.5 & 27 & - & - & $>8$ \\
\hline F2 & $25 / \mathrm{M}$ & Wrist (L) & 3 & 20 & $3-5$ & - & - \\
\hline F3 & $25 / M$ & Carpal-metacarpal $^{\mathrm{b}}(\mathrm{R})$ & 3.5 & 33 & $>8$ & - & - \\
\hline F4 & $20 / M$ & Mid-radius (L) & 3.5 & 37 & - & $>8$ & - \\
\hline F5 & $46 / M$ & Proximal Phalanges (L) & 4 & 18 & $<3$ & - & - \\
\hline F6 & $48 / M$ & Mid-metacarpal (L) & 4 & 31 & $5-8$ & $(\text { or } 5-8)^{c}$ & - \\
\hline F7 & $55 / F$ & Mid-humerus (L) & 5 & 48 & - & - & $>8$ \\
\hline F8 & $43 / \mathrm{M}$ & Mid-radius (R) & 5 & 29 & $<3$ & - & - \\
\hline F9 & $30 / \mathrm{M}$ & Mid-radius (R) & 3.5 & 15 & $5-8$ & 1-2/week & - \\
\hline F10 & $42 / \mathrm{M}$ & Mid-carpal (R) & 6 & 27 & $>8$ & $1-2 /$ week & - \\
\hline F11 & $24 / M$ & Wrist (R) & 8 & 27 & - & $>8$ & - \\
\hline
\end{tabular}

${ }^{a} \mathrm{~L}=$ left side amputated, $\mathrm{R}=$ right side amputated.

${ }^{\mathrm{b}}$ Thumb intact.

${ }^{\mathrm{c}}$ Subject (F6) wore a mechanical prosthesis or a cosmetic prosthesis $(5-8 \mathrm{~h} /$ day) depending on his daily activities. -, n/a.

"pins and needles" only one of the 10 subjects who experienced a PL at the initial session reported feeling these "exteroceptive sensations" whereas, whereas five of the nine subjects with phantoms reported these qualities at follow-up. Thus there was a significant increase in the number of subjects reported new PL sensation qualities at follow-up $\left(\chi^{2}=4.55, P<0.05\right)$.

Subjects $F 7$ and $F 11$ reported a telescoped limb at the initial session, and subjects $F 3$ and $F 11$ reported a telescoped limb at the follow-up session. Both subjects F3 and F7 had little or no PL pain at either session. Therefore we did not test the statistical relationship between telescoping and PL pain.

All three of the subjects who perceived dual percepts (i.e. a tactile-evoked percept localized to both the site of stimulation and the PL) (for a detailed description of dual percepts see Hunter et al., 2003, 2005) at the initial session continued to experience them at the follow-up session.

\section{Phantom pain}

Seven of the 11 subjects (63\%) continued to experience PL pain at follow-up. The prevalence of PL pain was not significantly different between the two sessions $\left(\chi^{2}=0.210\right.$, $P=1.00)$. Of the eight subjects $(72 \%)$ who reported experiencing $\mathrm{PL}$ pain at the initial session, the $\mathrm{PL}$ pain intensity decreased in seven subjects (mean decrease (S.E.) $=1.6$ $(0.47) \mathrm{cm}$ ) and increased in one subject (Table 2). PL pain was intermittent in five of the eight (63\%) subjects with PL pain at the initial session and in three of the seven (43\%) subjects with $\mathrm{PL}$ pain at the follow-up session. One subject (F8) with intermittent PL pain at the initial session reported that his PL pain was constant at the follow-up session. Of the eight subjects who continued to experience PL pain at the follow-up session, there were no obvious changes in pain quality of the individual's PL pain with the exception of some slight changes in location of pain and some new qualities (see Table 2).
SP

All but two subjects (F7, F11) had spontaneous SP at the initial session (prevalence $=91 \%$ ) (Table 2). At follow-up, 6 of the 11 subjects (54\%) reported experiencing SP within the preceding week. This change in prevalence was not statistically significant $\left(\chi^{2}=2.75, P=0.10\right)$ (Fig. 1). Two subjects (F2 and F3) had tactile hyperesthesia of the scar at the initial session that was not present at the follow-up session. One subject (F8) developed a defined area of tactile allodynia near the stump tip.

The most commonly reported evoked pain in the stump was a generalized allodynia (tenderness) to pressure, which was reported by nine subjects (F1-F3, F6-F11) at the initial session and five subjects (F2, F3, F6, F9, F11) at the follow-up session.

\section{Correlations between SP and phantom pain intensity}

Relationship between concurrent $S P$ and $P L$ pain intensity. Pearson linear correlation analysis revealed a significant relationship between the intensity of SP and intensity of PL pain, both at the initial session $(r=0.652$, $P<0.03)$, and at the follow-up session $(r=0.859, P<$ $0.001)$. Initial SP intensity had no effect on the relationship between SP and PL pain at follow-up $(r=0.849, P<0.002$, partial correlation controlling for initial SP). However, the follow-up SP-PL pain relationship was no longer significant when controlling for initial PL pain intensity $(r=0.167$, $P=0.65$, partial correlation controlling for initial PL pain). Thus, there was a significant relationship between SP and PL pain at the initial session, but the relationship between $\mathrm{SP}$ and $\mathrm{PL}$ pain at the follow-up session, while independent of initial SP intensity, was strongly influenced by initial $\mathrm{PL}$ pain intensity.

Follow-up SP: Longitudinal relationship to initial SP or to initial PL pain. Pearson linear correlation analysis revealed a significant relationship between initial and fol- 
Table 2. Intensity ratings for PL Awareness (PLA), PL Pain (PLP), and stump pain (SP), and description of PLA at the initial session (1) and follow-up session (2)

\begin{tabular}{|c|c|c|c|c|c|c|c|c|}
\hline \multirow{3}{*}{ Session } & \multicolumn{6}{|c|}{$\begin{array}{l}\text { Spontaneous sensations and pain intensity (rating } \\
\text { on a } 0-10 \text { scale }^{a} \text { ) }\end{array}$} & \multirow{2}{*}{\multicolumn{2}{|c|}{ Participant's qualitative description of phantom }} \\
\hline & \multicolumn{2}{|l|}{ PLA } & \multicolumn{2}{|l|}{ PLP } & \multicolumn{2}{|l|}{ SP } & & \\
\hline & 1 & 2 & 1 & 2 & 1 & 2 & 1 & 2 \\
\hline \multicolumn{9}{|l|}{ Subject } \\
\hline $\mathrm{F} 1$ & 9 & $9.5^{\mathrm{b}}$ & $7.2^{\mathrm{b}}$ & $4.6^{\mathrm{b}}$ & 2 & 2 & $\begin{array}{l}\text { Feels digits } 1,2 \text { and } 3 \\
\text { Clenched and "thumb over index } \\
\text { finger" }\end{array}$ & $\begin{array}{l}\text { Feels digits } 1 \text { and } 2 \\
\text { Resting position can move it a } \\
\text { little. Itching and tickling }\end{array}$ \\
\hline $\mathrm{F} 2$ & 8.3 & 7 & 7.6 & 7.1 & 4 & 5 & $\begin{array}{l}\text { Neutral or clenched nails digging into } \\
\text { palm }\end{array}$ & $\begin{array}{l}\text { Constant clenched fist } \\
\text { Nails not digging into palm } \\
\text { Tingling }\end{array}$ \\
\hline F3 & 9.8 & 9.6 & 0 & 0 & $2.5^{\mathrm{b}}$ & 0 & $\begin{array}{l}\text { Aware of digits } 4 \text { and } 5 \\
\text { Flexed-"stiff"-"feels like trying to } \\
\text { open" } \\
\text { Itching }\end{array}$ & $\begin{array}{l}\text { Aware of digits } 4 \text { and } 5 \\
\text { Flexed-"stiff" cramping "like } \\
\text { fingers are smaller and } \\
\text { telescoped into the numb area } \\
\text { of stump" } \\
\text { Itching, pins and needles }\end{array}$ \\
\hline F4 & 0 & 0 & 0 & 0 & $1^{\mathrm{b}}$ & 0 & No phantom & No phantom \\
\hline F5 & 1 & 0 & 0 & 0 & 2 & 0 & $\begin{array}{l}\text { Neutral, stiff "my hand wants to } \\
\text { move" }\end{array}$ & No phantom \\
\hline F6 & 8.5 & 9.2 & 4 & 3 & 1 & 2 & $\begin{array}{l}\text { Constant flexed slightly "Like } \\
\text { something is wound tight around } \\
\text { digit \#2" }\end{array}$ & $\begin{array}{l}\text { Constant flexed slightly, stiff, tight, } \\
\text { aware of fingers }\end{array}$ \\
\hline F7 & 8 & 10 & $1.5^{\mathrm{b}}$ & 0 & 2 & 0 & $\begin{array}{l}\text { Elbow flexed } 90^{\circ} \text { or normal length } \\
\text { but feels like fingers are pushed } \\
\text { into wrist }\end{array}$ & $\begin{array}{l}\text { Elbow flexed } 90^{\circ} \\
\text { Aware of fingers and elbow not } \\
\text { wrist or forearm. } \\
\text { Normal length. }\end{array}$ \\
\hline F8 & $9^{b}$ & 10 & $9.5^{\mathrm{b}}$ & 9.6 & $2.9^{\mathrm{b}}$ & 3.9 & $\begin{array}{l}\text { Digits } 1 \text { and } 2 \text { pinched with } 2 \text { and } 3 \\
\text { crossed. Does not feel forearm. No } \\
\text { other PLS just PLP }\end{array}$ & $\begin{array}{l}\text { Constant clenched fist Thumb } \\
\text { between digits } 2 \text { and } 3 \text {. Not } \\
\text { aware of forearm } \\
\text { Pins and needles }\end{array}$ \\
\hline F9 & 10 & $9^{b}$ & $8.5^{\mathrm{b}}$ & $7.5^{\mathrm{b}}$ & 8 & 7.5 & $\begin{array}{l}\text { Flexed slightly Fingers crossed and } \\
\text { feel "stuck in that position" } \\
\text { Tingling }\end{array}$ & $\begin{array}{l}\text { Slightly closed fist, feels stiff } \\
\text { Fingers feel stuck in that position. } \\
\text { "Feels like I want to open my } \\
\text { hand." }\end{array}$ \\
\hline F10 & 10 & 7.2 & 8 & 7.2 & 5 & 7 & $\begin{array}{l}\text { Constant fist, thumb under fingers, } \\
\text { pinching of fingernail }\end{array}$ & $\begin{array}{l}\text { Clenched fist. Fingers in cramped } \\
\text { position, pinching of finger nail, } \\
\text { itching, pins and needles }\end{array}$ \\
\hline F11 & 7 & 7 & $1^{\mathrm{b}}$ & $3^{\mathrm{b}}$ & 0 & 0 & $\begin{array}{l}\text { Vague clenched fist. Feels "like fist is } \\
\text { inside tip of stump trying to open." }\end{array}$ & $\begin{array}{l}\text { Vague clenched fist, "flushing" and } \\
\text { vague throbbing in palm and } \\
\text { one or two fingers. Sometimes } \\
\text { normal length, or clenched } \\
\text { inside arm. }\end{array}$ \\
\hline
\end{tabular}

${ }^{a}$ Within last 7 days.

b Intermittent.

low-up SP intensity $(r=0.870, P<0.001)$. PL pain had no effect on this relationship $(r=844, P<0.004$, partial correlation controlling for initial and follow-up PL pain). Thus the significant relationship between initial and follow-up SP intensity was independent of the intensity of PL pain.

Follow-up PL pain: Longitudinal relationship to initial $S P$ or to initial $P L$ pain. There was also a significant relationship between initial and follow-up PL pain intensity ( $r=0.956, P<0.001)$. Neither initial SP nor follow-up SP significantly affected this relationship $(r=0.930, P<0.001$, partial correlation controlling for initial SP; $r=0.824$, $P<0.003$, partial correlation controlling for follow-up SP). Thus the relationship between initial and follow-up PL pain intensity was independent of SP.

\section{Type of prosthesis vs. intensity of PL awareness and PL pain}

Prosthesis type affected $P L$ awareness but not $P L$ pain. The FP group included five subjects (F1, F4, F6, $F 7$, and F11) who regularly used a functional (mechanical or myoelectric) prosthesis for more than $5 \mathrm{~h}$ per day. The CP group included four subjects (F2, F3, F5, and $F 8$ ) who wore a CP only and two subjects (F9, F10) who generally wore and preferred a CP 5-8 h per day but occasionally wore a mechanical prosthesis.

At follow-up there was no difference between the FP and $C P$ groups in the intensity of $P L$ pain $(F(1,9)=2.31$; $P=0.16)$ or SP $(F(1,9)=3.99 ; P=0.08)$ or the vividness of $\mathrm{PL}$ awareness $(F(1,9)=0.00 P=0.99)$. Furthermore, prosthesis-use did not affect the stability of the intensity of PL 
Phantom Limb Awareness

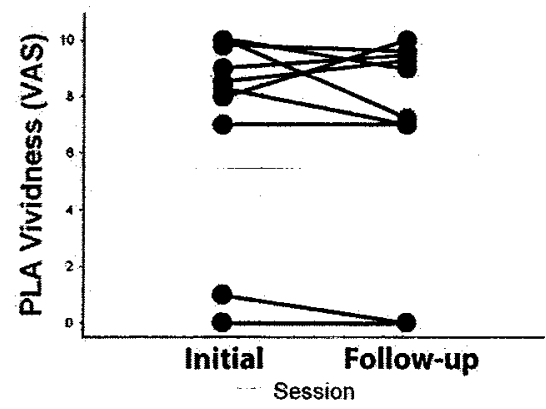

Phantom Limb Pain

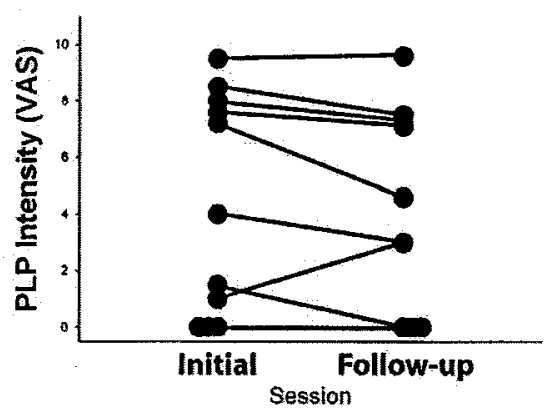

Stump Pain

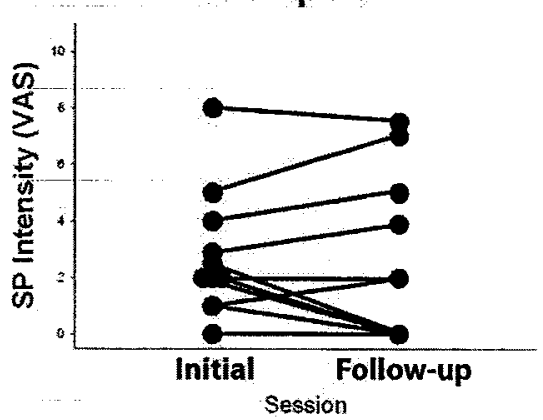

Fig. 1. Change in intensity between initial session and follow-up session. Each dot represents data from an individual subject at that session.

pain $(F(1,9)=0.120 ; P=0.74)$ or $\operatorname{SP}(F(1,9)=0.62$ $P=0.81)$. However not one subject in the FP group had a decrease in the perceived vividness of PL awareness at follow-up compared with the initial session; whereas five of the six subjects who used a CP had less vivid phantom sensations at follow-up compared with the initial session (Fig. 2). This difference in stability of vividness between the two prosthetic groups was significant $(F(1,9)=5.38 ; P<$ 0.05).

\section{Skin temperature}

In general, within each individual, the stump sites were cooler than corresponding sites on the intact contralateral side, and distal stump sites were cooler than proximal stump sites (Fig. 3). Mean skin temperature at both the distal and the proximal site was consistently lower on the amputated side compared with homologous sites on the intact side at both the initial measure and at the follow up measure (Fig. 3).

The side (amputated, intact) vs. site (proximal, distal) vs. session (initial, follow-up) ANOVA showed a statistically significant effect for side $(F(1,10)=8.595, P=0.015)$ and site $(F(1,10)=12.643, P=0.005)$ but not for session $(F(1,10)=0.977, P=0.346)$. Significant interactions were found between session and site $(F(1,10)=8.345, P=$ $0.0 .16)$, and between side and site $(F(1,10)=17.865, P=$ $0.002)$.
Individual pairwise comparisons for simple main effects of the side vs. site interaction effect showed a significantly lower temperature at the distal vs. proximal site on the affected side $(P<0.001)$ but not on the intact side $(P=0.07)$ and a significantly lower temperature on the amputated vs. intact side at the distal site $(P<0.002)$ but not at the proximal site $(P=0.215)$. Individual pairwise comparisons for simple main effect of the session vs. site interaction effect showed a significantly lower temperature at the distal vs. proximal site at the follow-up session $(P<0.001)$ but not at initial session $(P=0.680)$.

The above analysis revealed a significantly lower skin temperature of the distal stump site at follow-up. The distal stump was cooler than the proximal site or the homologous contralateral site at each session and it also was significantly cooler at follow-up than at the initial session. However, skin temperature on the distal affected side site did not correlate significantly with pain intensity (stump or phantom) at either the initial $(r=0.08, P=0.81, r=0.03$, $P=0.94$ respectively) or the follow-up session ( $r=0.19$, $P=0.58 ; r=0.35, P=0.46$, respectively). Nor was there a significant correlation between intersessional change in side-to-side skin temperature difference and the intersessional change in $\mathrm{PL}$ pain intensity $(r=-0.40, P=0.91)$, SP intensity $(r=0.256 . P=0.45)$, or $P L$ vividness $(r=-0.46$, $P=0.89)$.
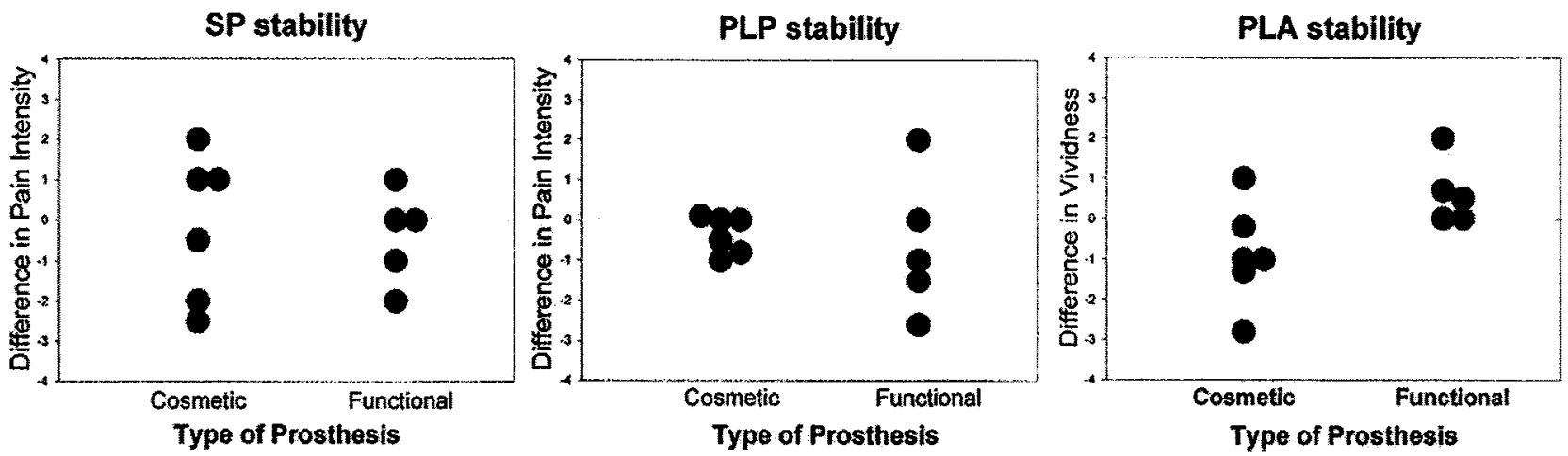

Fig. 2. The impact of cosmetic and functional (mechanical or myoelectric) prosthesis use on perception was assessed by the difference between scores obtained at follow-up score minus the original session scores. Each dot represents the difference score from an individual subject. Plotted are scores for SP intensity (left), PL pain (PLP) intensity (middle) and PL awareness (PLA) vividness (right). 


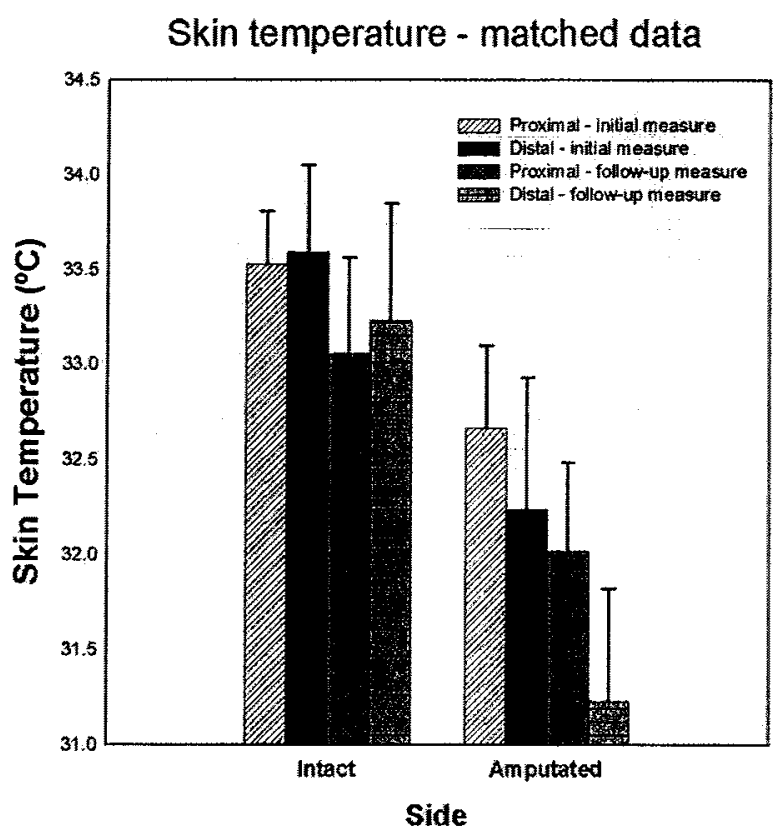

Fig. 3. Skin temperature summary data. Mean ( $t$ S.E.) skin temperature at the distal site (or stump tip) and the proximal site. Sites were determined on the amputated side and then homologous contralateral sites were chosen on the intact side. Main effects of three-way repeated measure ANOVA shows that the amputated side is significantly cooler than the intact side $(P=0.015)$ and distal site is significantly cooler than proximal $(P=0.005)$. The interaction between session and side was not significant

\section{Tactile testing}

Subjective reports of tactile sensitivity. Two subjects reported tactile allodynia to light touch in the scar area (operative site) only at the initial visit but not a follow-up. Nine subjects at the initial session and six at follow-up reported that the general area of stump tip was "sensitive" to a "tap" or "pressure" stimulus incurred during normal day-to-day activities. Localized sensitivity suggestive of a neuroma was described in three subjects (subjects F5, F6, and $F 11$ ) at the initial session and three subjects (subjects $F 1, F 6$, and F11) at follow-up.

Tactile detection thresholds normalized at follow-up. Tactile detection thresholds in the proximal sites ranged from $0.068 \mathrm{~g}$ to $0.692 \mathrm{~g}$, which is within the normal range as described by Bell-Krotoski et al. (1995). Tactile detection thresholds at healthy skin areas were within normal limits with the exception of one subject (F8). At the initial session tactile thresholds at the operative site ranged from $0.068 \mathrm{~g}$ to $125.893 \mathrm{~g}$ reflecting areas of poor sensation over healing scar tissue in six subjects in whom tactile thresholds were elevated. At follow-up the thresholds improved toward normal values. Only two subjects had side-to-side tactile differences where tactile threshold was higher than normal at the operative site as follows: F3 (15.136 g) and F6 (3.631 g).

Tactile acuity was stable between sessions. Two-point discrimination thresholds were measured at each session at two locations (healthy skin and scarred skin) on the distal stump tip. Side-to-side comparison of thresholds at the follow-up session revealed that two-point discrimination thresholds were not significantly different on the two limbs except in the scar area of the operative site. However thresholds at each side were stable over time. That is, the thresholds at the operative site did not change between the initial session and the follow-up session, and the thresholds in healthy looking skin adjacent to the scar area did not change. Prosthesis-use did not affect the stability of the two-point discrimination thresholds $(F(1,9)=4.069 ; P=$ 0.74).

\section{DISCUSSION}

These longitudinal data provide new information on the stability and inter-relationships between post-amputation sensory sequelae, and have particular importance because they were obtained from a cohort without longstanding pre-amputation pain or coexisting medical conditions (e.g. diabetes or vascular or neurological disease) that would impede normal sensory function or peripheral vascular function. In addition, the recruiting strategy ensured that the sample was inclusive of all traumatic upper extremity amputees who were attending rehabilitation at the two participating hospitals and was not biased to those with unique sensory symptoms or pain.

\section{PL awareness}

The most salient finding of this study is that the general awareness of a PL can persist in terms of intensity and position for up to 4 years after unilateral traumatic upper extremity amputation. This is in contrast to variability in the prevalence, quality, and intensity of stump and phantom sensory sensations and pain. We previously differentiated between PL sensations and PL awareness (Hunter et al., 2003). PL sensations include those feelings with specific somatic exteroceptive and/or proprioceptive characteristics, such as tingling, itching, pressure, movement, warmth, or cold in the missing limb, whereas PL awareness refers to a general conscious awareness of a body part, including the size and position of the part, without actually feeling any specific somatic sensation (Hunter et al., 2003, 2005). Few studies collect or report data specifically on PL awareness (Halligan, 2002; Flor et al., 2006). Previously reported examples of what we have labeled "PL awareness" include phantom phenomena that were described by some authors as "phantoms with no description," but may also include phantoms that were described as "proprioceptive or kinesthetic perceptions" (Jensen et al., 1983; Montoya et al., 1997; Richardson et al., 2006). Montoya et al. (1997) reported that the magnitude (i.e. the product of intensity $\times$ frequency) of "kinesthetic" (feelings of size, shape, or weight of the limb) and the magnitude of "kinetic" (feelings of voluntary movement of the limb) PL awareness were each significantly greater than the magnitude of "exteroceptive" PL sensations. Based on our evaluation of the integration of vision, touch, and sensorimotor inputs on PL awareness (Hunter et al., 2003), we previously argued that PL awareness reflects altered body 
schema perpetuated by conflicting sensorimotor information pertaining to the state of the motor system.

The prevalence $(81 \%)$ of PL concurs with that reported in a longitudinal study by Jensen et al. (1984). Some retrospective studies or cross-sectional studies have concluded that the painless PL eventually disappears with time. Data from the present cohort do not indicate this tendency at least up to 4 years after amputation. The impression that PL disappears with time may be explained by differences in data acquisition methodology combined with a focus on PL sensations only. For example, the prevalence of $P L$ is higher in studies where subjects are interviewed (Cronholm, 1951; Haber, 1956; Varma and Mukherjee, 1972; Carlen et al., 1978; Shukla et al., 1982) vs. those that collected data by ad hoc questionnaires or specific questionnaires that focused on exteroceptive qualities of the pain experience. Among our subjects, the most common and persistent PL phenomena described was an awareness of the position of the limb and not the perception of exteroceptive phantom sensations. The phantom hand was felt as either neutral or in a flexed position and "stiff," "clenched," or "tight"; and this was consistent over both sessions. Previous studies where subjects were interviewed, noted similar descriptions (Cronholm, 1951; Haber, 1956; Carlen et al., 1978; Fraser et al., 2001; Richardson et al., 2006). Thus, to obtain data about PL awareness, questionnaires must be modified appropriately and validated to systematically collect data including this aspect of the PL experience.

\section{PL sensations}

At follow-up, we found a significant increase in the number of subjects who reported the experience of the PL sensory qualities of "tickling," "tingling," and "pins and needles." Similarly, Jensen followed 58 lower extremity amputees and reported that the "character of the experienced volume" of the nonpainful PL was similar to that reported at 6 months, whereas the number of people who reported experiencing only "tingling, itching, or a feeling of warmth or cold" increased significantly over the same time period (Jensen et al., 1984).

Ectopic discharge caused by altered electrical properties of damaged axons, neuromas, or dorsal root ganglion cells, is a potential mechanism for these spontaneous PL sensations or pain (Devor and Seltzer, 1999). The ectopic activity in myelinated axons may precede that occurring in unmyelinated axons (Devor and Seltzer, 1999). The variation in the latency of the injury-induced changes in conduction properties of damaged peripheral axons may explain the changes in the characteristics of PL sensations that occur over time.

\section{PL pain}

The prevalence of PL pain after upper extremity amputation was consistent at both sessions in this study. Of the subjects with PL pain, the pain was intermittent in approximately $60 \%$ at both the initial session and at follow-up. This agrees with a longitudinal study by Jensen et al. (1985) where the incidence of PL pain remained relatively constant over 2 years following lower extremity amputation. However, in that study only $20 \%$ of the subjects who reported phantom pain 2 years after amputation had daily PL pain occurrences (Jensen et al., 1985). In a survey of 255 lower extremity amputees several months or years after amputation, $81 \%$ of those reporting $\mathrm{PL}$ pain stated that it was episodic in nature (Ehde et al., 2000). In fact, $50 \%$ of the subjects experienced PL pain less than once per week (Ehde et al., 2000). Similarly, in a group of 92 lower extremity amputees only $37 \%$ of the group who reported $\mathrm{PL}$ pain experienced it more than half of the time (Smith et al., 1999). Careful interviewing of 76 upper extremity amputees showed that only $24 \%$ of those reporting $\mathrm{PL}$ pain had daily occurrences (Fraser et al., 2001). Thus, in contrast to $\mathrm{PL}$ awareness there is a subset of amputees in whom PL pain remains constant and a subset in whom $P L$ pain is intermittent.

\section{Concurrent and predictive relationships between SP and PL pain}

With respect to the relationship between the intensities of SP and PL pain within and between the two sessions, the strongest relationship was between initial and follow-up SP and between initial and follow-up PL pain. Given, that PL pain and SP can occur together, especially in the early months after amputation, analysis of the subsequent SP-PL pain relationship must consider the possible influence of initial PL pain or SP as a covariate. In our study, partial correlation controlled for this. Although SP and PL pain were significantly correlated at the initial session and at follow-up session, the SP-PL pain relationship at follow-up was no longer significant when initial PL pain was considered as a covariate. Likewise, initial SP intensity did not predict follow-up PL pain intensity nor did initial PL pain intensity predict follow-up SP intensity.

This lack of relationship between SP and PL pain at follow-up is consistent with the results of four studies (Jensen et al., 1985; Nikolajsen et al., 1997; Fraser et al., 2001; Gallagher et al., 2001). One of these studies found a significant relationship between $\mathrm{PL}$ pain and SP at 1 week but not at 3 months or 6 months (Nikolajsen et al., 1997). In contrast, four previous studies (Nikolajsen et al., 1997; Kooijman et al., 2000; Dijkstra et al., 2002; Richardson et al., 2007) found that significantly more subjects with SP (vs. without SP) also reported PL pain. However, these studies relied on retrospective accounts of pain and analyzed the relationship by classifying subjects dichotomously as "pain" or "no pain." The intermittent nature of $P L$ pain affects prevalence statistics and therefore the calculated relationship between SP and PL pain can be influenced by the criteria used to dichotomize the frequency and intensity of $\mathrm{PL}$ pain into pain vs. no pain groups (Borsje et al., 2004). In addition, retrospective evaluations of pain are variable (Redelmeier and Kahneman, 1996) and can be influenced by present pain (Eich et al., 1985; Feine et al., 1998; Linton and Melin, 1982; Linton, 1991; Nikolajsen et al., 1997). In contrast, we collected pain intensity data longitudinally and did not divide subjects into 
pain vs. no pain groups, but instead we compared intensity of the pains.

Our findings indicate that the SP and PL pain each reflect a distinct combination of underlying mechanisms. Given the strong relationship between initial and follow-up SP and between initial and follow-up PL pain, the persistence of these pains could be explained at least in part by the pain memory hypothesis (Katz and Melzack, 1990; Flor, 2002; Flor et al., 2006). Pain memories are central changes in somatosensory processing induced by initial nociceptive input. Previous studies have shown that chronic pre-amputation pain predicts initial PL pain (Nikolajsen et al., 1997; Hanley et al., 2007). Our subjects had no longstanding pre-amputation pain, and no complicating disease that would contribute to the development of persistent pain. Traumatic amputation involves a significant afferent barrage that may induce central sensitization in adjacent dermatomes. However, we found no evidence of a generalized spinal cord hyperexcitability, as tactile thresholds in skin areas adjacent to injured nerves were normal. Thus more longitudinal research is needed to evaluate predictors of chronic SP vs. PL pain.

\section{Effect of prosthesis-use}

The change in PL pain intensity between the initial and follow-up sessions was no different in those subjects who used a FP compared with those that used a CP. Our findings with respect to the relationship between prosthesis-use and PL pain contrast with those in two retrospective studies (Weiss et al., 1999; Lotze et al., 1999). However, the differences in age and time post-amputation as well as recruitment strategies, in addition to the retrospective questioning about pain intensity, made it difficult to compare the prosthetic vs. the control groups in those studies. Our conclusions are limited because of the small number of subjects and because there was no comparable subset of subjects who did not use a prosthesis at all. Nevertheless, our longitudinal data support the notion that prosthesis-use does not influence $\mathrm{PL}$ pain intensity over time This lack of relationship between prosthesis-use and PL pain is supported by studies of upper extremity amputees (Wartan et al., 1997; Kooijman et al., 2000), lower extremity amputees (Gallagher et al., 2001), or in studies that evaluated both upper extremity and lower extremity amputees (Sherman et al., 1984; Jensen et al., 1985; Wartan et al., 1997; Dijkstra et al., 2002).

Interestingly, prosthesis-use may maintain or increase vividness of the $\mathrm{PL}$ awareness over time. Functional use of a prosthesis correlated with stable or slightly increased vividness of $\mathrm{PL}$ awareness whereas those subjects who used a CP had less vivid PL awareness at follow-up.

Finally, even though there was considerable variability in prosthesis-use between session 1 and session 2, there was no concomitant change in sensory function in the tactile pathway. Tactile thresholds did not change over time in any subject and prosthesis-use did not affect the stability of the two-point discrimination thresholds or $\mathrm{PL}$ pain intensity. Spatial acuity testing can reflect the amount of brain area devoted to the sensation (Merzenich et al.,
1984; Recanzone et al., 1992) and improved tactile spatial and temporal acuity may correlate with $\mathrm{S} 1$ reorganization (Flor et al., 2001). Thus we found no link between prosthesis-use and reorganization in the tactile pathway that could explain the increased vividness of PL awareness. This, taken together with our findings on the effect of prosthesis-use on PL awareness, and the unique nature of $P L$ awareness, suggests that future studies are needed to evaluate the relationship between prosthesis-use, PL awareness, and changes in processing of body schema.

\section{Stump skin temperature and phantom phenomena}

Stump skin temperature was consistently cooler than the intact limb at both proximal and distal sites. Previous cross-sectional studies have also reported that the residual limb can be cooler than the unaffected limb (Angrilli and Koster, 2000; Sliosberg, 1948). Sherman and Bruno (1987) proposed that the coolness of the stump reflected sympathetic hyperactivity, causing reduced blood flow to the stump and, secondarily, increased pain. These authors reported an inverse correlation between fluctuations in PL pain intensity and stump skin temperature. However, these findings are complicated by lack of a control group and the fact that many of the subjects had both SP and PL pain. Katz (1992a) showed that in the absence of SP, both painful and non-painful PL phenomena are associated with a lower stump skin temperature. Surface skin temperature reflects cutaneous blood flow but has a complex relationship to sympathetic activity (Katz, 1992a). Our study evaluated whether limb temperature per se correlated with the intensity of PL pain. It is the first to evaluate this relationship in a cohort of subjects without concurrent disease that would have impacted peripheral nerve function. The sideto-side difference in skin temperature did not correlate with current average stump or PL pain intensity at the initial or at the follow-up session. In addition, although we found significant change in the skin temperature of the distal stump between session 1 and session 2, this skin temperature change did not correlate with the inter-session change in PL awareness, sensations, pain, or SP. Therefore, limb temperature was not directly related to intensity of SP or PL phenomena.

\section{Limitations}

These findings are limited by the small number of subjects and are limited to the time period evaluated (from 2.5 months to 48 months after amputation). The large number of statistical tests reflects the exploratory nature of this longitudinal study. Corrections for numbers of tests were accordingly made for each set of tests. We found no validated measure to compare prosthesis-use, and thus based the FP/CP classification on whether or not individuals used a FP to manipulate objects, a procedure that requires motor training. This did not preclude those in the $\mathrm{CP}$ group from using the $\mathrm{CP}$ or the stump to stabilize objects in bilateral tasks. We used threshold measures of tactile function. Thus, abnormal responses could reflect dysfunction anywhere in this system, from the peripheral receptors to the cortex (Verdugo and Ochoa, 1992; Shy et 
al., 2003). Although, two-point discrimination can detect both positive and negative changes in sensory function, additional measures to detect positive phenomena (e.g. hyperalgesia) would provide additional information on CNS processing of tactile information. In addition, the contralateral side was used for comparison for all psychophysical and skin temperature measures. This may have made it more difficult to detect significantly abnormal thresholds since simultaneous appearance of bilateral pain hypersensitivity following unilateral nerve injury has been noted in animal models of post-traumatic painful neuropathy (Koltzenburg et al., 1999), thus indicating potential bilateral sensory abnormalities. However, these tactile thresholds were consistently within normal limits in our subjects.

\section{CONCLUSION}

In summary, longitudinal data from our unselected cohort, without complicating disease, injury or pre-amputation pain provide useful information about the somatosensory consequences of amputation. First, our data show that the pattern of sensory abnormalities can vary between subjects with similar injuries. Second, sensory processing of tactile information from the stump remains stable over the time period examined, and there is no evidence of a generalized excitability in dermatomes adjacent to the injured nerve. Third, with respect to abnormal sensory perceptions, our data indicate that PL awareness is distinct from $P L$ sensations and PL pain. PL awareness is a consistent post-amputation phenomenon whereas $\mathrm{PL}$ sensations and PL pain are less prevalent and vary individually over the time period examined in this study (i.e. from the early months after amputation until more than 2 years after amputation). Fourth, chronic SP and PL pain each reflect a distinct combination of underlying mechanisms, and early PL pain, not SP, predicts later PL pain. Finally, PL awareness, sensations, and pain were not related in any simple way to peripheral sensory function, SP, or limb temperature. PL awareness (not PL pain) may be influenced frequent use of a FP. We previously proposed that PL awareness reflects altered body schema in response to conflicting sensorimotor information pertaining to the state of the motor system (Hunter et al., 2003). Future study is needed to evaluate the incongruence hypothesis (Flor et al., 2006) in maintaining $\mathrm{PL}$ awareness. We recommend that $\mathrm{PL}$ awareness, PL sensations, PL pain, and SP should be evaluated as distinct post-amputation sensory dysfunctions, each with a unique combination of underlying mechanisms.

Acknowledgments-J. P. Hunter was supported by a Canadian Institutes of Health Research-Strategic Training Program in Cell Signaling, Mucosal Inflammation and Pain, University of Toronto Centre for the Study of Pain-Clinician-Scientist Award, and a joint research partnership between St. John's Rehabilitation Hospital and West Park Health care Centre. J. P. Hunter is currently a Canadian Paraplegic Association (Ontario) Postdoctoral Fellow at Toronto Rehab Institute, Toronto, Ontario, Canada. K. D. Davis holds a Canada Research Chair in Brain and Behavior. This study was partially supported by funds made available from the Canada
Research Chair program. J. Katz is supported by a Canada Research Chair in Health Psychology at York University.

\section{REFERENCES}

Angrilli A, Koster U (2000) Psychophysiological stress responses in amputees with and without phantom limb pain. Physiol Behav 68:699-706.

Bell-Krotoski JA, Fess EE, Figarola JH, Hiltz D (1995) Threshold detection and Semmes-Weinstein monofilaments. $J$ Hand Ther 8:155-162.

Borsje S, Bosmans JC, van der Schans CP, Geertzen JH, Dijkstra PU (2004) Phantom pain: a sensitivity analysis. Disabil Rehabil 26:905-910.

Carlen PL, Wall PD, Nadvorna $H_{s}$ Steinbach T (1978) Phantom limbs and related phenomena in recent traumatic amputations. Neurology 28:211-217.

Cronholm B (1951) Phantom limbs in amputees. Acta Psychiat Neurol Scand Suppl Suppl 72:1-310.

Devor M, Seltzer Z (1999) Pathophysiology of damaged nerves in relation to chronic pain. In: Textbook of pain, 4th edition (Wall PD, Melzack R, eds), pp 129-164. Edinburgh: Churchill Livingstone.

Dijkstra PU, Geertzen JH, Stewart R, van der Schans CP (2002) Phantom pain and risk factors: a multivariate analysis. J Pain Symptom Manage 24:578-585.

Ehde DM, Czerniecki JM, Smith DG, Campbell KM, Edwards WT, Jensen MP, Robinson LR (2000) Chronic phantom sensations, phantom pain, residual limb pain, and other regional pain after lower limb amputation. Arch Phys Med Rehabil 81:1039-1044.

Eich E, Reeves JL, Jaeger B, Graff-Radford SB (1985) Memory for pain: relation between past and present pain intensity. Pain 23:375-380.

Feine JS, Lavigne GJ, Dao TT, Morin C, Lund JP (1998) Memories of chronic pain and perceptions of relief. Pain 77:137-141.

Flor $H$ (2002) Painful memories: Can we train chronic pain patients to "forget" their pain? EMBO Rep 3:288-291.

Flor H, Denke C, Schaefer M, Grusser S (2001) Effect of sensory discrimination training on cortical reorganisation and phantom limb pain. Lancet 357:1763-1764.

Flor $\mathrm{H}$, Elbert T, Knecht $\mathrm{S}$, Wienbruch $\mathrm{C}$, Pantev $\mathrm{C}$, Birbaumer $\mathrm{N}$, Larbig W, Taub E (1995) Phantom-limb pain as a perceptua correlate of cortical reorganization following arm amputation. Nature 375:482-484

Flor H, Nikolajsen L, Staehelin JT (2006) Phantom limb pain: a case of maladaptive CNS plasticity? Nat Rev Neurosci 7:873-881.

Fraser CM (1998) An evaluation of the use made of cosmetic and functional prostheses by unilateral upper limb amputees. Prosthet Orthot Int 22:216-223.

Fraser CM, Halligan PW, Robertson IH, Kirker SG (2001) Characterising phantom limb phenomena in upper limb amputees. Prosthet Orthot Int 25:235-242.

Gallagher P, Allen D, Maclachlan M (2001) Phantom limb pain and residual limb pain following lower limb amputation: a descriptive analysis. Disabil Rehabil 23:522-530.

Haber WB (1956) Observations on phantom-limb phenomena. Arch Neurol Psychiatry :624-636.

Halligan PW (2002) Phantom limbs: The body in mind. Cogn Neuropsychiatry 7:251-268.

Hanley MA, Jensen MP, Smith DG, Ehde DM, Edwards WT, Robinson LR (2007) Preamputation pain and acute pain predict chronic pain after lower extremity amputation. J Pain 8:102-109.

Hunter JP, Katz J, Davis KD (2005) Dissociation of phantom limb phenomena from stump tactile spatial acuity and sensory thresholds. Brain 128:308-320.

Hunter JP, Katz J, Davis KD (2003) The effect of tactile and visual sensory inputs on phantom limb awareness. Brain 126:579-589.

Jenkins WM, Merzenich MM, Ochs MT, Allard T, Guic-Robles E (1990) Functional reorganization of primary somatosensory cortex in adult 
owl monkeys after behaviorally controlled tactile stimulation. J Neurophysiol 63:82-104.

Jensen TS, Krebs B, Nielsen J, Rasmussen P (1983) Phantom limb, phantom pain and stump pain in amputees during the first 6 months following limb amputation. Pain 17:243-256.

Jensen TS, Krebs B, Nielsen J, Rasmussen P (1984) Non-painful phantom limb phenomena in amputees: incidence, clinical characteristics and temporal course. Acta Neurol Scand 70:407-414.

Jensen TS, Krebs B, Nielsen J, Rasmussen P (1985) Immediate and long-term phantom limb pain in amputees: incidence, clinical characteristics and relationship to pre-amputation limb pain. Pain 21:267-278

Katz J (1992a) Psychophysical correlates of phantom limb experience. J Neurol Neurosurg Psychiatry 55:811-821.

Katz J (1992b) Psychophysiological contributions to phantom limbs. Can J Psychiatry 37:282-298.

Katz J, Melzack R (1990) Pain "memories" in phantom limbs: review and clinical observations. Pain 43:319-336.

Koltzenburg M, Wall PD, McMahon SB (1999) Does the right side know what the left is doing? Trends Neurosci 22:122-127.

Kooijman CM, Dijkstra PU, Geertzen JH, Elzinga A, van der Schans CP (2000) Phantom pain and phantom sensations in upper limb amputees: an epidemiological study. Pain 87:33-41.

Linton SJ (1991) Memory for chronic pain intensity: correlates of accuracy. Percept Mot Skills 72:1091-1095.

Linton SJ, Melin L (1982) The accuracy of remembering chronic pain. Pain 13:281-285.

Lotze M, Grodd W, Birbaumer N, Erb M, Huse E, Flor H (1999) Does use of a myoelectric prosthesis prevent cortical reorganization and phantom limb pain? Nat Neurosci 2:501-502.

Mannion RJ, Woolf $\mathrm{CJ}$ (2000) Pain mechanisms and management: a central perspective. Clin J Pain 16:S144-S156.

Melzack R (1990) Phantom limbs and the concept of a neuromatrix. Trends Neurosci 13:88-92.

Merzenich MM, Nelson RJ, Stryker MP, Cynader MS, Schoppmann A, Zook JM (1984) Somatosensory cortical map changes following digit amputation in adult monkeys. J Comp Neurol 224:591-605.

Montoya P, Larbig W, Grulke N, Flor H, Taub E, Birbaumer N (1997) The relationship of phantom limb pain to other phantom limb phenomena in upper extremity amputees. Pain 72:87-93.

Moseley GL (2006) Graded motor imagery for pathologic pain: a randomized controlled trial. Neurology 67:2129-2134.

Nikolajsen L, Ilkjær S, Kroner K, Christensen JH, Jensen TS (1997) The influence of preamputation pain on postamputation stump and phantom pain. Pain 72:393-405.

Nikolajsen L, Jensen TS (2005) Phantom limb. In: Wall and Melzack's textbook of pain, 5th edition (McMahon S, Koltzenburg M, eds), pp 961-971. Philadelphia: Elsevier/Churchill Livingstone.

Recanzone $\mathrm{GH}$, Merzenich MM, Jenkins WM, Grajski KA, Dinse HR (1992) Topographic reorganization of the hand representation in cortical area $3 \mathrm{~b}$ owl monkeys trained in a frequency-discrimination task. J Neurophysiol 67:1031-1056.

Redelmeier DA, Kahneman D (1996) Patients' memories of painful medical treatments: real-time and retrospective evaluations of two minimally invasive procedures. Pain 66:3-8.

Richardson C, Glenn S, Horgan M, Nurmikko T (2007) A prospective study of factors associated with the presence of phantom limb-pain six months after major lower limb amputation in patients with peripheral vascular disease. J Pain 8:793-801.

Richardson C, Glenn S, Nurmikko T, Horgan M (2006) Incidence of phantom phenomena including phantom limb pain 6 months after major lower limb amputation in patients with peripheral vascular disease. Clin J Pain 22:353-358.

Sherman RA (1997) Phantom pain. New York: Plenum Press.

Sherman RA, Bruno GM (1987) Concurrent variation of burning phantom limb and stump pain with near surface blood flow in the stump. Orthopedics 10:1395-1402.

Sherman RA, Sherman CJ, Parker L (1984) Chronic phantom and stump pain among American veterans: results of a survey. Pain 18:83-95.

Shukla GD, Sahu SC, Tripathi RP, Gupta DK (1982) Phantom limb: a phenomenological study. Br J Psychiatry 141:54-58.

Shy ME, Frohman EM, So YT, Arezzo JC, Cornblath DR, Giuliani MJ, Kincaid JC, Ochoa JL, Parry GJ, Weimer LH (2003) Quantitative sensory testing: report of the Therapeutics and Technology Assessment Subcommittee of the American Academy of Neurology. Neurology 60:898-904

Sliosberg A (1948) Les algies des amputés, pp 80-81. Paris: Masson et Cie.

Smith DG, Ehde DM, Legro MW, Reiber GE, del Aguila M, Boone DA (1999) Phantom limb, residual limb, and back pain after lower extremity amputations. Clin Orthop Relat Res 361:29-38.

Steinbach TV, Nadvorna H, Arazi D (1982) A 5-year follow-up study of phantom limb pain in post traumatic amputees. Scand $\mathrm{J}$ Rehabil Med 14:203-207.

Varma SK, Mukherjee A (1972) A study of phantom experience in amputees. Indian J Med Sci 26:185-188.

Verdugo R, Ochoa JL (1992) Quantitative somatosensory thermotest. A key method for functional evaluation of small calibre afferent channels. Brain 115(Pt 3):893-913.

Wartan SW, Hamann W, Wedley JR, McColl I (1997) Phantom pain and sensation among British veteran amputees. $\mathrm{Br} J$ Anaesth 78:652-659.

Weiss T, Miltner WH, Adler T, Bruckner L, Taub E (1999) Decrease in phantom limb pain associated with prosthesis-induced increased use of an amputation stump in humans. Neurosci Lett 272:131134.

Woolf CJ, Mannion RJ (1999) Neuropathic pain: aetiology, symptoms, mechanisms, and management. Lancet 353:1959-1964. 